\title{
Local and Remote Impacts of Aerosol Climate Forcing on Tropical Precipitation*
}

\author{
CHIA CHOU \\ Research Center for Environmental Changes, Academia Sinica, Taipei, Taiwan \\ J. DAVID NEELIN \\ Department of Atmospheric Sciences, and Institute of Geophysics and Planetary Physics, University of California, Los Angeles, \\ Los Angeles, California \\ ULRIKE LOHMANN \\ Institute of Atmospheric and Climate Science, ETH Zürich, Zürich, Switzerland \\ JOHANN FEICHTER \\ Max Planck Institute for Meteorology, Hamburg, Germany
}

(Manuscript received 18 October 2004, in final form 10 May 2005)

\begin{abstract}
Mechanisms that determine the direct and indirect effects of aerosols on the tropical climate involve moist dynamical processes and have local and remote impacts on regional tropical precipitation. These mechanisms are examined in a climate model of intermediate complexity [quasi-equilibrium tropical circulation model (QTCM)] forced by prescribed aerosol forcing, which is obtained from a general circulation model (ECHAM4). The aerosol reflection is the dominant aerosol forcing, while the aerosol absorption has complex but much weaker influences on the regional tropical precipitation based on the ECHAM4 aerosol forcing. The local effect associated with aerosols contributes negative precipitation anomalies over convective regions by affecting the net energy flux into the atmospheric column. This net energy flux is controlled by the radiative forcing at the top of the atmosphere on time scales where surface heat flux is near equilibrium, balancing anomalous solar radiation by evaporation, longwave radiation, and sensible heat. Considering the aerosol absorption effect alone, the associated precipitation anomalies are slightly negative but small when surface heat fluxes are near equilibrium. Two effects found in global warming, the uppedante mechanism and the anomalous gross moist stability mechanism, occur with opposite sign in the aerosol case. Both act as remote effects via the widespread cold tropospheric temperature anomalies induced by the aerosol forcing. In the upped-ante mechanism in global warming, a warm troposphere increases the lowlevel moisture "ante" required for convection, creating spatially varying moisture anomalies that disfavor precipitation on those margins of convective zones where the mean flow imports air from nonconvective regions. In the aerosol case here, a cool troposphere preferentially decreases moisture in convective regions, creating positive precipitation anomalies at inflow margins. In the anomalous gross moist stability mechanism for the aerosol case, the decrease in moisture in convective regions acts to enhance the gross moist stability, so convection and the associated precipitation are reduced. The partitioning between the aerosol local and remote effects on regional tropical precipitation differs spatially. Over convective regions that have high aerosol concentration, such as the South American region, the aerosol local effect contributes more negative precipitation anomalies than the anomalous gross moist stability mechanism in the QTCM simulations. On the other hand, the remote effect is more important over convective regions with small aerosol concentrations, such as the western Pacific Maritime Continent. Remote effects of midlatitude aerosol forcing have a substantial contribution to tropical anomalies.
\end{abstract}

* Institute of Geophysics and Planetary Physics, University of California, Los Angeles Contribution Number 6213.

Corresponding author address: Dr. Chia Chou, Research Center for Environmental Changes, Academia Sinica, P.O. Box 1-48, Taipei 11529, Taiwan.

E-mail: chiachou@rcec.sinica.edu.tw

(C) 2005 American Meteorological Society 


\section{Introduction}

Aerosols create great uncertainties in studying climate change under global warming. Aerosols directly affect the climate system by scattering and absorbing solar radiation. These "direct" effects can cool both the atmosphere and surface by reflecting solar radiation back into space. At the same time, the direct effects can also warm the atmosphere by absorbing solar radiation, but this absorption cools the surface. These effects change the temperature structure and then influence the strength of convection (Kaufman et al. 2002). The absorption effect mainly induced by black carbon warms the atmosphere (Jacobson 2001) but is hypothesized to reduce the convection contribution to warming the atmosphere (Ramanathan et al. 2001; V. Ramanathan 2004, personal communication). Aerosols can also increase cloud drop number concentration and reduce cloud drop effective radius, so clouds exist longer and precipitation efficiency is decreased. These "indirect" effects can lead to a weaker hydrological cycle (Feichter et al. 2004; Liepert et al. 2004; Ramanathan et al. 2001). The feedback of smaller cloud drop effective radius and longer lifetimes of clouds tends to reflect more solar radiation and further cool the climate system (Lohmann and Lesins 2002; Penner et al. 2004). Overall, the aerosol climate forcing tends to partly offset the global warming impacts associated with greenhouse gases (GHGs). However, the aerosol lifetime is much shorter than that of most GHGs and the aerosol concentration varies strongly with space, so the aerosol climate impact cannot be treated as a mirror image of global warming (Houghton et al. 2001; Rotstayn and Lohmann 2002). Finally, Feichter et al. (2004) noted that the nonlinear interaction between aerosol particles and GHG weakens the warming tendency dominated by GHG.

Considering the GHG warming alone, the radiative effects have a very broad spatial pattern. The associated tropospheric temperature anomalies are relatively uniform, while the precipitation anomalies are much more complex and have strong spatial variations. Studies of global warming impacts on precipitation show poor agreement among climate model simulations on a regional basis (Allen and Ingram 2002; Neelin et al. 2003, hereafter NCS03). To understand the mechanisms of global warming impacts on regional tropical precipitation, Chou and Neelin (2004, hereafter CN04) have proposed two dominant mechanisms: the anomalous gross moist stability $\left(M^{\prime}\right)$ mechanism and the upped-ante mechanism. As the troposphere warms, the low-level moisture tends to increase to maintain convective quasi equilibrium $(\mathrm{QE})$ in convective regions.
This effect linking the tropospheric temperature and the low-level moisture is termed "QE mediation" [Neelin and Su 2005; CN04 focused on convective available potential energy (CAPE), but QE mediation is a more general term for this effect]. Over nonconvective regions, the low-level moisture is controlled by different processes that cause smaller increases in the low-level moisture, such as the balance between divergence and evaporation. Thus, a spatial gradient of anomalous lowlevel moisture is induced. This coexistence of the smooth anomalous temperature distribution and the strong horizontal gradient of moisture anomalies is critical to inducing regional tropical precipitation changes. In the $M^{\prime}$ mechanism, gross moist stability is reduced by the increases in low-level moisture, so convection is enhanced and precipitation increases over convective regions. In the upped-ante mechanism, inflow of air with less positive moisture anomalies from nonconvective regions into margins of convective regions opposes the low-level moisture increases. As a result, the low-level moisture does not increase enough to meet the higher "convective ante" needed to maintain the convection in the face of warmer tropospheric temperature aloft. The precipitation is thus reduced over margins of convective regions wherever there is strong inflow. This upped-ante mechanism is also found in the reduction of precipitation over equatorial South America and the Atlantic intertropical convergence zone (ITCZ) during El Niño events (NCS03).

Regional tropical precipitation changes induced by the aerosol effects are also complex (Feichter et al. 2004) and have aspects similar to the global warming case. Aerosol distribution is rather regional and the distribution of greenhouse gases is global. To what extent are mechanisms of tropical precipitation impacts similar or different between the global warming and aerosol cases? To answer this question, examination of the aerosol effects without interaction with global warming should be conducted. The separation of aerosol and GHG effects may imply caveats because of nonlinear interaction between aerosol effects and GHG effects, such as in Feichter et al. (2004). However, this kind of experiment can be a prelude to examining more complex cases of simultaneously competing greenhouse and aerosol effects. In this study, an atmospheric model of intermediate complexity (Neelin and Zeng 2000; Zeng et al. 2000) is used. This model is coupled with a mixed layer ocean model (Chou et al. 2001) and is forced by prescribed aerosol forcing. Throughout this paper, "aerosol effects" will be used to mean combined direct and indirect effects as estimated from anthropogenic sulfate and carbonaceous aerosols in Feichter et al. (2004). The quasi-equilibrium tropical circulation 
model (QTCM) is a special purpose primitive equation model designed to aid understanding of interaction of tropical deep convection with large-scale dynamics. A number of cases of such interaction have already been worked out, including ENSO teleconnections (Su et al. 2001; Su and Neelin 2002) and greenhouse gas response (Chou and Neelin 2004; Neelin et al. 2003). To the extent that the ECHAM4 tropical response to aerosols can be reproduced in the QTCM when given forcing from ECHAM4, theory developed in prior work can aid in unraveling the causal pathways. Furthermore, the forcing can be decomposed in a number of ways since running a series of long experiments with different subsets of the forcing fields is straightforward in QTCM.

Considering the aerosol case without any influence of greenhouse gases, the aerosol forcing cools the climate system in general. Figure 1 shows the aerosol climate impacts in the boreal winter, including direct and indirect effects, from the fourth-generation Max Planck Institute for Meteorology model, ECHAM4, coupled to a slab ocean and thermodynamic sea ice model (Feichter et al. 2004). The troposphere does become colder globally. The temperature anomalies over the Northern Hemisphere are stronger than those in the Southern Hemisphere, and the temperature anomalies show little

(a) Prec Diff (DJF): ECHAM4

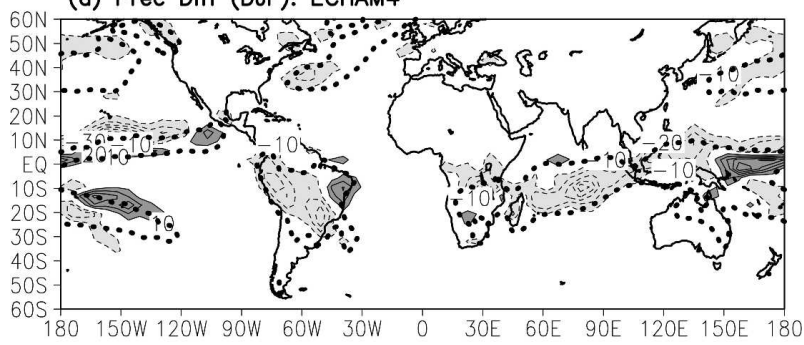

(b) $\mathrm{T}(850-200 \mathrm{hPa})$ Diff

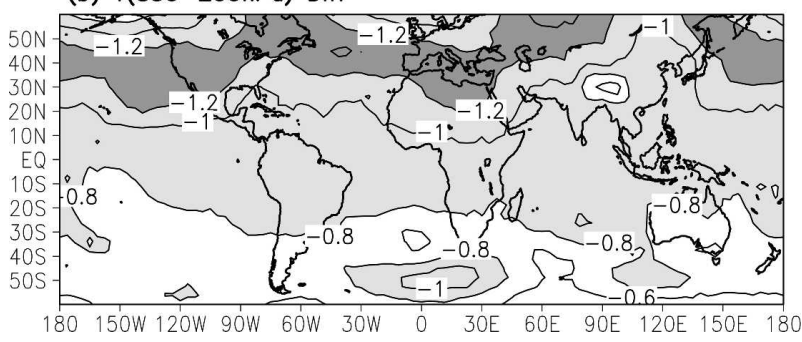

FIG. 1. (a) DJF precipitation and (b) tropospheric temperature (850-200 hPa) differences between the ECHAM4 present day (PD) and preindustrial (PI) simulations. The thick dashed line in (a) is $150 \mathrm{~W} \mathrm{~m}^{-2}$ contour from the DJF precipitation climatology. Contour interval is $10 \mathrm{~W} \mathrm{~m}^{-2}$ for precipitation. Dark shading is above $30 \mathrm{~W} \mathrm{~m}^{-2}$ and light shading is below $-30 \mathrm{~W} \mathrm{~m}^{-2}$. Contour interval is $0.2^{\circ} \mathrm{C}$ for temperature. Dark shading is above $1.2^{\circ} \mathrm{C}$ and light shading is between $0.8^{\circ}$ and $1.2^{\circ} \mathrm{C}$. Precipitation is given in $\mathrm{W}$ $\mathrm{m}^{-2}$ for comparison to energy budgets. Divide by 28 to obtain $\mathrm{mm}$ day $^{-1}$. longitudinal gradient. This broad cooling pattern hints at a potential connection with the global warming case in terms of mechanisms affecting regional tropical precipitation since widespread tropospheric temperature anomalies occur in both cases. The precipitation anomalies in Fig. 1a show strong spatial variations and occur mostly in the Tropics, especially over the tropical oceans. This spatial pattern of the precipitation anomalies does exhibit qualitative similarities in some regions to the global warming case (e.g., Fig. 2a of CN04), but with opposite sign. Negative precipitation anomalies occur over convective regions and positive anomalies are found over margins of convective regions for the aerosol case, and vice versa for the global warming case. To what extent mechanisms have similar pathways between the global warming and the aerosol cases presents an interesting question and will be examined in this study.

Figure 2 shows the aerosol solar radiative forcing in the boreal winter. The associated longwave radiative forcing (not shown) is much smaller. Thus, only the solar component of the aerosol radiative effect is pre-

\section{(a) FSW Diff (DJF): ECHAM4}

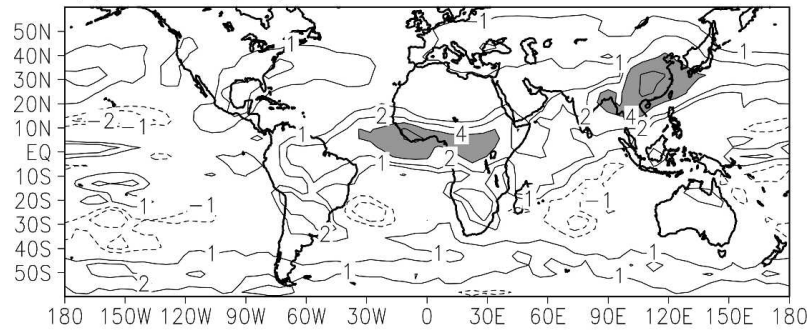

(b) FSWut Diff

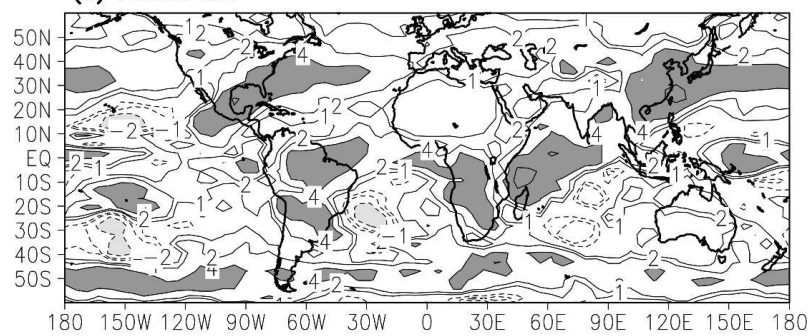

(c) FSWs Diff

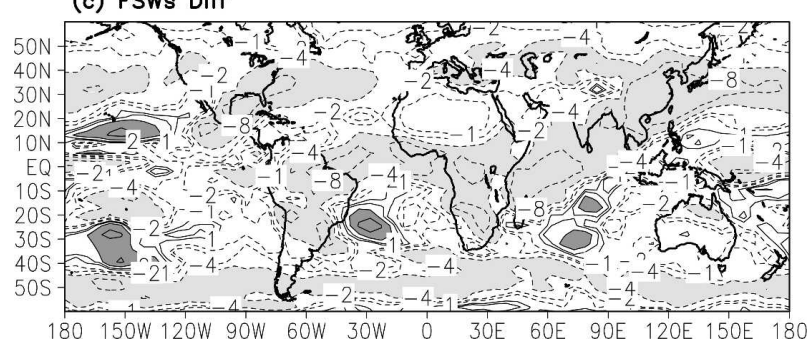

FIG. 2. ECHAM4 aerosol forcing for DJF. (a) Solar absorption by the atmosphere $\left(S_{t}^{\downarrow}-S_{t}^{\uparrow}-S_{s}^{\downarrow}+S_{s}^{\uparrow}\right)$, (b) solar reflection at the TOA $\left(S_{t}^{\uparrow}-S_{t}^{\downarrow}\right)$, and (c) net solar absorption by the surface $\left(S_{s}^{\downarrow}-\right.$ $S_{s}^{\uparrow}$ ). Contour interval is $4 \mathrm{~W} \mathrm{~m}^{-2}$. Dark shading is above $8 \mathrm{~W} \mathrm{~m}^{-2}$ and light shading is below $-8 \mathrm{~W} \mathrm{~m}^{-2}$. 
scribed as forcing in this study. The aerosol forcing, which includes reflection and absorption, has a much more complex spatial distribution than the forcing associated with greenhouse gases, which is fairly uniform in space. Figure 2a shows solar absorption, which is dominated by absorbing aerosols such as carbonaceous particles. Two maximum regions are found over Southeast Asia and West Africa with values around $8 \mathrm{~W} \mathrm{~m}^{-2}$. Figure $2 \mathrm{~b}$ shows solar reflection at the top of the atmosphere (TOA), which is controlled by nonabsorbing aerosols such as sulfate particles, and the associated indirect feedback of this interaction with cloud microphysics. The distribution of the aerosol reflection differs from that of the absorption, and there are five maximum areas: Southeast Asia, the southeastern part of North America, South America, South Africa, and the western Indian Ocean. The maximum amplitude of the aerosol reflection is similar to that of absorption, but the global average of the aerosol reflection is stronger since its distribution is much broader than that of the aerosol absorption. Both aerosol absorption and reflection reduce downward solar insolation, so the net solar absorption by the surface is reduced more than the reflection at the TOA.

With the aerosol forcing in Fig. 2, we examine the aerosol effects on regional tropical precipitation. The models and the forcing strategy used in this study are described in section 2. Simulated impacts of aerosol absorption and reflection effects are examined together and separately in section 3. In section 4, a moist static energy budget analysis approach is outlined with proposed mechanisms and diagnostics of these. Experiments to separate aerosol local and remote effects are presented in section 5, with discussion in section 6 .

\section{Models and forcing strategy}

\section{a. Models}

The aerosol model used here is coupled with the atmospheric general circulation model (GCM) ECHAM4; a complete description can be found in Feichter et al. (2004). Below is a brief description of the aerosol model. The aerosol concentration is predicted from the aerosol budget, which is controlled by processes of emissions, transport, chemical transformation, dry and wet deposition, and sedimentation. The aerosol components include sulfate, black carbon, organic carbon, mineral dust, and sea salt. The physical and optical aerosol properties that are used to calculate the direct aerosol effect are specified from observations for each component. The aerosol number concentration can modify cloud microphysics and induces the indirect aerosol effect; for example, it enhances cloud albedo through reduction of the droplet effective radius and increase of cloud droplet number concentration as described by Lohmann et al. (1999, 2000).

The ECHAM4 atmospheric GCM with the aerosol model is coupled to a slab ocean model with a depth of $50 \mathrm{~m}$ (Roeckner et al. 1995) and a thermodynamic sea ice model. Using the ECHAM4 model, a pair of experiments is used to examine aerosol impacts on climate. The first experiment is for preindustrial (PI) conditions with PI aerosol and aerosol precursor emissions of sulfate and organic carbon. The second experiment is for present-day (PD; mid-1980s) conditions with PD aerosol and aerosol precursor emissions of sulfate and black and organic carbon. The greenhouse gases are constant at the PD level in both experiments. Thus, differences between the PD and PI experiments are purely caused by aerosol effects, including both direct and indirect effects. The results shown in this study are for 50-yr averages after $20 \mathrm{yr}$ of integration to reach approximate climate equilibrium.

To examine the aerosol effects on regional precipitation, a coupled ocean-atmosphere-land model of intermediate complexity (Neelin and Zeng 2000; Zeng et al. 2000, hereafter ZNC) with prescribed divergence of ocean heat transport ( $Q$ flux) is used (Chou et al. 2001). Based on the analytical solutions derived from the Betts-Miller moist convective adjustment scheme (Betts and Miller 1993), typical vertical structures of temperature, moisture, and winds for deep convection are used as leading basis functions for a Galerkin expansion (Neelin and Yu 1994; Yu and Neelin 1994). The resulting primitive equation model makes use of constraints on the flow by quasi-equilibrium thermodynamic closures and is referred to as QTCM1 (quasiequilibrium tropical circulation model with a single vertical structure of temperature and moisture for deep convection). Because the basis functions are based on vertical structures associated with convective regions, these regions are expected to be well represented and similar to a GCM with the Betts-Miller moist convective adjustment scheme. Far from convective regions, QTCM1 is a highly truncated Galerkin representation equivalent to a two-layer model. A cloud-radiation scheme (Chou and Neelin 1996; ZNC), simplified from the full GCM radiation schemes (Harshvardhan et al. 1987; Fu and Liou 1993), is included. Deep convection and cirrocumulus/cirrostratus cloud fraction is estimated by an empirical parameterization (Chou and Neelin 1999). A simple formula is used to obtain atmospheric boundary layer winds under assumptions of a steady state and a vertically homogeneous mixed layer with fixed height (Stevens et al. 2002). An intermediate land surface model (ZNC) is used to simulate interac- 
tion between the atmosphere and land surface. This model simulates processes such as evapotranspiration and surface hydrology in a single land surface layer for calculating energy and water budgets. Soil moisture is balanced by precipitation, evaporation, surface runoff, and ground runoff. QTCM version 2.3 is used here with the solar radiation scheme slightly modified using the new $\mathrm{Fu}$ and Liou radiation scheme.

\section{b. Forcings and experiments}

Motivated by the strong spatial pattern of the tropical precipitation change induced by aerosol effects, we attempt to understand the mechanisms of these aerosol impacts using the QTCM forced by prescribed ECHAM4 aerosol radiative forcing (Feichter et al. 2004). Because indirect aerosol effects are included, direct implementation of aerosol particles in QTCM is not appropriate. Thus, the aerosol forcing needs to include changes in solar radiation associated with changes in cloud properties, such as cloud droplet effective radius. A portion of the cloud change is due to dynamical feedback, but it is hard to partition this effect. Therefore, we use total solar radiation changes as forcing and "freeze" the QTCM solar radiation deep-convection cloud feedback by using fixed cloud cover to avoid counting this effect twice. Moreover, since the role of deep-convection cloud feedback is reasonably understood in QTCM and it is secondary in global warming simulations (CN04), this assumption of freezing solar radiation cloud feedback is a reasonable case in which to examine aerosol effects. All longwave radiative feedbacks are treated with the standard QTCM version 2.3 parameterizations. Since mechanisms for inducing the precipitation anomalies do not depend significantly on season when considering the first-order effects of aerosol, we present the December-February (DJF) season only in this study. Moreover, DJF can avoid some complications involved with the Asian summer monsoons, which are not simulated well by most climate models.

We first aim to reproduce general features of the ECHAM4 runs in QTCM. Two components of the aerosol forcing associated with solar radiation, net solar radiative fluxes at the top of the atmosphere (TOA) and at the surface, are prescribed in QTCM. Since there is only one thermodynamic equation in QTCM1, this is sufficient to get projection onto the temperature basis function response. To examine changes associated with absorption versus reflection of solar radiation, the aerosol forcing is decomposed into two cases: One case assumes pure absorption by aerosols and no change due to the aerosol forcing at TOA. The converse case has no absorption in the atmosphere by aerosols with changes in net surface solar radiation identical to TOA reflection. In the case of aerosol absorption, the net solar absorption in the atmosphere is matched to the ECHAM4 runs and surface solar radiation is reduced correspondingly. For the aerosol reflection case, we use the TOA solar radiation changes from the ECHAM4 simulations, and surface solar radiation anomalies are reduced by the same amount so that atmospheric absorption is zero. Another useful aspect of this decomposition is that solar radiative forcing anomalies of the two cases add up to the total ECHAM4 forcing. Thus, if the responses are approximately linear, they can be used to compare to the full forcing response.

One caveat on this decomposition of the forcing is that it is not identical to running a full radiative transfer calculation with absorption and reflection set to zero in turn. Setting absorption to zero in such a calculation would change TOA forcing slightly and, in the converse case, pure absorption would have a small TOA component due to surface albedo. However, the decomposition used here appears useful for understanding the impacts of each process.

Other cases are used to evaluate local versus remote response. Over a region of interest, such as South America, the solar radiative forcing is set to zero, so remote response over this region to the outside forcing can be examined. To examine local response, a converse experiment with the aerosol forcing only over this region is performed. The target region considered here is tropical South America, which has a large deep convection zone and large aerosol forcing. Another experiment is to examine impacts of the midlatitude aerosol forcing on tropical climate. In this experiment, the aerosol forcing over the band region between $20^{\circ}$ and $50^{\circ} \mathrm{N}$ where most aerosol particles are emitted is prescribed, but the aerosol forcing outside the band region is set to zero. To identify how the aerosol forcing remotely affects the tropical precipitation, an experiment is also conducted with modified tropospheric temperature obtained from the full aerosol experiment specified in the convective scheme.

To have a signal with statistical significance, especially for those experiments with small changes, a longterm average is needed. Moreover, the long-term average can help us to identify regional climate changes more precisely. Thus, results of all experiments with QTCM are 400-yr averages.

\section{Response to aerosol solar forcing and absorption versus reflection components}

\section{a. Total response}

The first experiment examines how well QTCM can reproduce the response to the aerosol effects found in 
the ECHAM4 simulation. Forced by the prescribed net solar radiation anomalies at the TOA and the surface, the results of the QTCM simulation are shown in Fig. 3. Comparing to the ECHAM4 runs in Fig. 1, the exact positions of the precipitation anomalies are not the same, but the positions relative to the preindustrial mean precipitation in each model are very similar. The negative precipitation anomalies are located over deep convective regions, while the positive anomalies are found over the margins of deep convective regions. Two areas with anomalies of opposite sign to the global warming case are well simulated: South America and the central Pacific. The anomalies over South America will be discussed as an example in the following sections. The amplitudes of the precipitation anomalies in the QTCM and ECHAM4 runs are comparable. The tropospheric temperature anomalies in the QTCM simulations are similar to those in the ECHAM4 simulations with a smoother spatial pattern and slightly weaker amplitude. Overall, QTCM reproduces the anomalies induced by the aerosol effects found in the ECHAM4 simulations, so QTCM can be used to further examine the aerosol effects.

\section{b. Absorption versus reflection components}

To examine the aerosol absorption and reflection effects separately, two experiments described in section $2 \mathrm{~b}$ are performed, and the results are shown in Figs. 4 and 5. Forced only by the reflection effect, the results in Fig. 4 show similar patterns of precipitation and tropo-

(a) Prec Diff (DJF): QTCM (control)

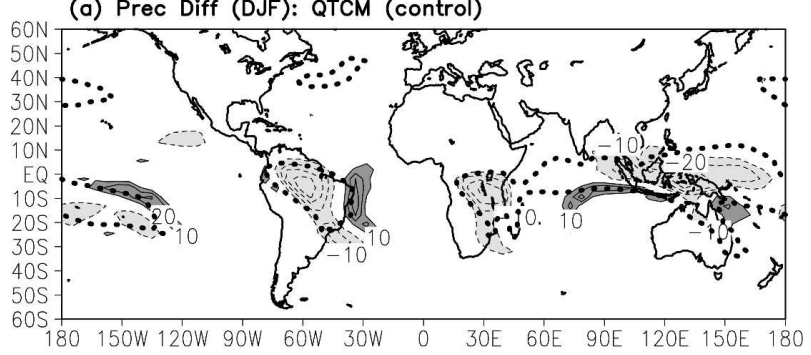

(b) $\mathrm{T}(850-200 \mathrm{hPa})$ Diff

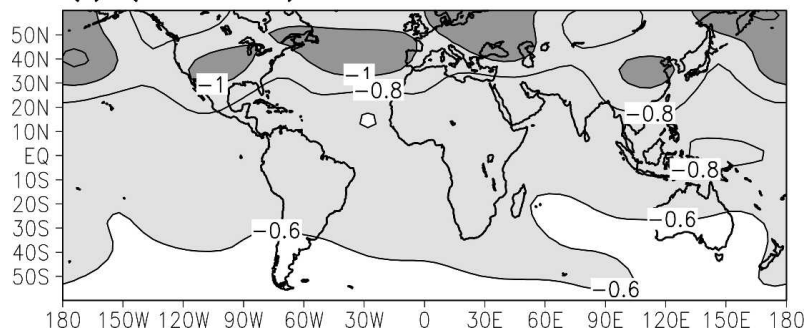

FIG. 3. As in Fig. 1 except for the QTCM simulations of PD PI differences: (a) precipitation and (b) temperature. Dark shading is above $1.0^{\circ} \mathrm{C}$ and light shading is between $0.6^{\circ}$ and $1.0^{\circ} \mathrm{C}$ (different from Fig. 1). (a) Prec Diff (DJF): QTCM (fsw=0)

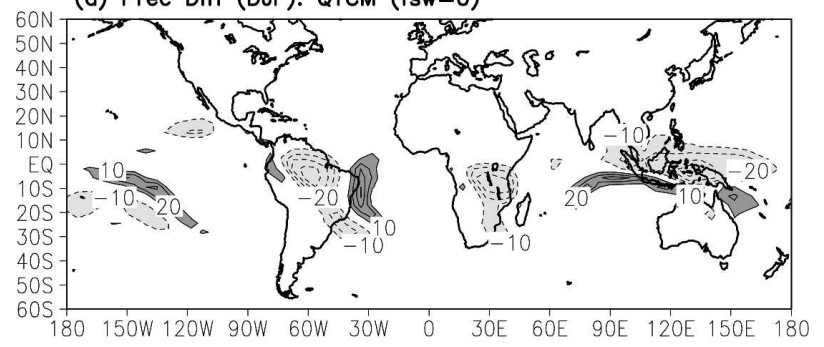

(b) $\mathrm{T}(850-200 \mathrm{hPa})$ Diff

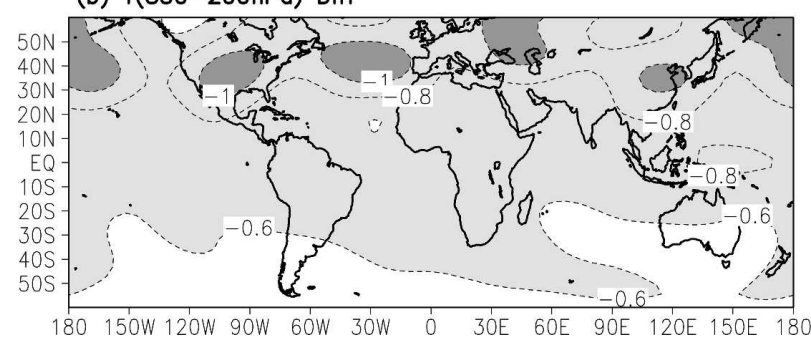

FIG. 4. As in Fig. 3 except for the experiment with the aerosol reflection only.

spheric temperature anomalies to those in Fig. 3. However, the results, in Fig. 5, that are forced only by the absorption effect are much weaker than those in Fig. 4. This indicates that the aerosol solar reflection is the leading effect on changing tropical precipitation and is much more effective than the aerosol absorption. The tropospheric temperature anomalies induced by the aerosol absorption (not shown) are also weaker than those induced by the solar reflection. Their magnitude is less than $0.05^{\circ} \mathrm{C}$ in the Tropics, so little remote effect associated with the tropospheric temperature changes should be expected. These results are surprising because both aerosol absorption and reflection effects cool the surface and their amplitudes are relatively comparable (Fig. 2). The reduced surface solar radiation is balanced by evaporation and surface longwave radiation anomalies, so the net surface heat flux anomalies are close to zero at a time scale when land

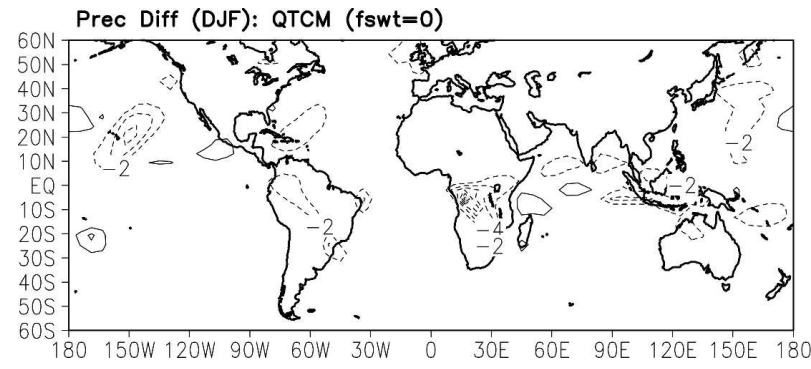

FIG. 5. As in Fig. 3 except for precipitation of the experiment with the aerosol absorption only. Contour interval is $2 \mathrm{~W} \mathrm{~m}^{-2}$ (different from Fig. 3). 
and ocean surfaces reach equilibrium (Liepert et al. 2004). Thus, the net radiation anomaly at the TOA becomes crucial in determining the aerosol effects. For the reflection experiment (Fig. 4), the aerosol TOA forcing is similar to the control experiment in Fig. 3, so the aerosol climate impacts in both experiments are similar. For the absorption experiment (Fig. 5), the aerosol TOA forcing is zero by definition, so changes induced by the aerosol absorption are small. The mechanism associated with the net radiative flux anomalies at the TOA will be discussed in detail in section $4 \mathrm{~b}$. The combination of the precipitation anomalies induced by the aerosol absorption and reflection, respectively (Figs. 4 and 5), tends to be close to that in Fig. 3. This implies that the aerosol absorption and reflection effects are relatively linear in their impact on atmospheric dynamics.

\section{Diagnosis of mechanisms}

\section{a. Moist static energy budget}

In general, the aerosol effects cool the climate system and reduce global precipitation. On a regional basis, both positive and negative precipitation anomalies are found. This indicates that more complex processes are involved in determining regional precipitation anomalies. Thus, we analyze moisture and moist static energy budgets to understand mechanisms of the regional tropical precipitation anomalies caused by the aerosol effects. Under the quasi-equilibrium convective closure, the anomaly moisture budget integrated through the troposphere for a steady state can be written as

$$
P^{\prime} \approx \bar{M}_{q} \nabla \cdot \mathbf{v}_{\mathbf{1}}^{\prime}+M_{q}^{\prime} \nabla \cdot \overline{\mathbf{v}}_{\mathbf{1}}-\langle\mathbf{v} \cdot \nabla q\rangle^{\prime}+E^{\prime},
$$

where an overbar denotes averaged variables without aerosol impacts, primes represent the anomalies caused by aerosol effects, $P$ is precipitation, $E$ is evaporation, $\mathbf{v}$ is horizontal velocity, and $g$ is gravity. Angle brackets denote a vertical integral over the troposphere with $p_{T}$ as the depth of the troposphere:

$$
\langle X\rangle=\frac{1}{g} \int_{p_{s}}^{p_{s}-p_{T}} X d p,
$$

where $p_{s}$ is surface pressure. The specific humidity $q$ is in energy units (absorbing the latent heat per unit mass, $L)$. The horizontal velocity $\mathbf{v}_{\mathbf{1}}$ is the wind component associated with baroclinic structure under convective quasi-equilibrium constraints, and $M_{q}$ is the gross moisture stratification (Neelin and Yu 1994; Yu et al. 1998) and is given by

$$
M_{q}=\left\langle\Omega \partial_{p} q\right\rangle,
$$

where $\Omega(p)$ is the vertical structure of vertical velocity from baroclinic wind and

$$
\omega(x, y, p, t)=-\Omega(p) \boldsymbol{\nabla} \cdot \mathbf{v}_{\mathbf{1}}(x, y, t),
$$

where $\omega$ is pressure velocity. Thus, (1) uses

$$
-\left\langle\omega \partial_{p} q\right\rangle \approx M_{q} \boldsymbol{\nabla} \cdot \mathbf{v}_{\mathbf{1}},
$$

with $M_{q}$ giving the amount of moisture convergence produced per unit of low-level convergence/upper-level divergence in the baroclinic flow.

The precipitation anomaly in (1) is dominated by $\left(M_{q} \boldsymbol{\nabla} \cdot \mathbf{v}_{\mathbf{1}}\right)^{\prime}$, which is mainly determined by $\boldsymbol{\nabla} \cdot \mathbf{v}_{\mathbf{1}}^{\prime}$ in the Tropics. Note that $\boldsymbol{\nabla} \cdot \mathbf{v}_{\mathbf{1}}>0$ indicates low-level convergence and upper-level divergence. To estimate $\boldsymbol{\nabla} \cdot \mathbf{v}_{\mathbf{1}}^{\prime}$ the vertically integrated moist static energy budget is used. Under similar assumptions to (1), the vertically integrated moist static energy equation can be written as

$$
\bar{M} \nabla \cdot \mathbf{v}_{\mathbf{1}}^{\prime}=F^{\mathrm{net}^{\prime}}-M^{\prime} \nabla \cdot \overline{\mathbf{v}}_{\mathbf{1}}-\langle\mathbf{v} \cdot \nabla(q+T)\rangle^{\prime},
$$

where $T$ is atmospheric temperature $\left(\mathrm{J} \mathrm{kg}^{-1}\right.$, absorbing the heat capacity at constant pressure, $\left.C_{p}\right)$. The net energy input into the atmospheric column $F^{\text {net }}$ is given by

$$
F^{\text {net }}=F_{t}-F_{s}
$$

where the net heat flux at the TOA can be obtained by

$$
F_{t}=S_{t}^{\downarrow}-S_{t}^{\uparrow}-R_{t}^{\uparrow}
$$

and the net heat flux at the surface is from

$$
F_{s}=S_{s}^{\downarrow}-S_{s}^{\uparrow}+R_{s}^{\downarrow}-R_{s}^{\uparrow}-E-H .
$$

Subscripts $s$ and $t$ on the solar $\left(S^{\downarrow}\right.$ and $\left.S^{\uparrow}\right)$ and longwave ( $R^{\uparrow}$ and $R_{\downarrow}$ ) radiative terms denote surface and model top, and $R_{t}^{\downarrow} \approx 0$ has been used; $H$ is sensible heat flux. Positive values of $F_{t}$ and $F_{s}$ indicate downward heat fluxes, and $M$ is the gross moist stability (Neelin and $\mathrm{Yu}$ 1994; Yu et al. 1998), defined by

$$
M=\left\langle\Omega\left(-\partial_{p} h\right)\right\rangle,
$$

where $h=s+q$ is moist static energy and $s=T+\phi$ is dry static energy, with $\phi$ the geopotential. Thus, (6) uses

$$
\left\langle\omega \partial_{p} h\right\rangle \approx M \nabla \cdot \mathbf{v}_{\mathbf{1}} .
$$

More detailed derivations of the moisture and moist static energy budget equations can be found in CN04 and $\mathrm{Su}$ and Neelin (2002). Following Neelin and $\mathrm{Su}$ (2005), eliminating $\boldsymbol{\nabla} \cdot \mathbf{v}_{\mathbf{1}}^{\prime}$ between (6) and (1) yields 


$$
\begin{aligned}
P^{\prime}= & \frac{\bar{M}_{q}}{\bar{M}}\left[-\langle\mathbf{v} \cdot \nabla T\rangle^{\prime}+F_{t}^{\prime}-F_{s}^{\prime}\right]+E^{\prime}-\left(\frac{\bar{M}_{q}}{\bar{M}}+1\right) \\
& \times\langle\mathbf{v} \cdot \nabla q\rangle^{\prime}+\left(-\frac{\bar{M}_{q}}{\bar{M}} M^{\prime}+M_{q}^{\prime}\right) \nabla \cdot \overline{\mathbf{v}}_{1} .
\end{aligned}
$$

The enhancement of terms in the moist energy budget (by a factor of $\bar{M}_{q} / \bar{M}$ ) in forcing precipitation is termed the gross moist stability multiplier effect. In deep convective regions, $\bar{M}_{q} / \bar{M} \approx 4$ in this model, consistent with estimate in Yu et al. (1998), where values in the range 3-7 were obtained.

\section{b. Implications for the solar absorption forcing case}

The aerosol absorption effect is highly uncertain (Ramanathan et al. 2001) and is dependent on the vertical distribution of aerosol (Hansen et al. 1997). The surface boundary condition is also crucial. For instance, Menon et al. (2002) use fixed SST and find that aerosol absorption heats the atmosphere and enhances regional convection and the associated precipitation. This is because any solar radiation reaching the surface is assumed lost into an infinite heat capacity ocean. In the fixed SST case, aerosol absorption produces heating in the atmosphere that is not compensated by changes in surface fluxes and can thus affect precipitation. When the surface layer is allowed to equilibrate, as in the QTCM simulations with a mixed layer ocean here, very different balances apply. An increase in solar absorption in the atmosphere implies an equal reduction in downward insolation at the surface. When the surface layer equilibrates, this is compensated by reductions in the upward flux into the atmosphere by the sum of other surface fluxes. The net effect on the column-integrated energy input is zero. The leading-order impact in the fixed SST case is thus removed, as elaborated below, and any impacts on precipitation must come from more subtle effects, such as the partition among evaporation and other surface fluxes. In the QTCM experiments, even though the solar absorption forcing (Fig. 2a) is almost as strong as the TOA forcing (Fig. 2b), the precipitation anomalies are much weaker (Fig. 5 compared to Fig. 4a). Based on (6), $F^{\text {net' }}$ plays an important role in determining low-level divergence associated with convection. Since $F_{s}^{\prime}=0$ is often found over land and is small under oceanic equilibrium, $F^{\mathrm{net}^{\prime}} \approx F_{t}^{\prime}$. The TOA forcing associated with $F_{t}^{\prime}$ becomes the leading role in moist dynamical processes. The solar radiative flux anomalies at the TOA are zero by definition in the solar absorption forcing case, so the precipitation anomalies are small. The precipitation anomalies do not fit well with respect to the effect of aerosol solar absorption in tropical convective zones, which would be expected from one-dimensional radiative-convective balance (e.g., Cess et al. 1985; Ramanathan et al. 2001; V. Ramanathan 2004, personal communication). In this balance, convection does not have to transport as much heat upward, so convection becomes weaker to compensate increased solar absorption in the atmosphere. The sign of the precipitation anomalies in the QTCM simulations is consistent with this argument, but the anomalies are strongly offset in space from the regions of strongest solar absorption (Fig. 2a).

Table 1 contrasts the three-dimensional (3D) case relevant here with the one-dimensional (1D) case often considered for aerosol impacts for the case of land or an equilibrated mixed layer ocean where $F_{s}^{\prime}=0$. In the 1D case, $F_{t}^{\prime}=0$ in equilibrium due to longwave balancing aerosol shortwave effects. In the $3 \mathrm{D}$ case, $F_{t}^{\prime}$ can have substantial local anomalies since wave dynamics spreads temperature anomalies, so longwave balance of localized shortwave anomalies occurs over broad regions. Thus TOA aerosol impacts can be more important in 3D than in $1 \mathrm{D}$, especially since they induce a multiplier effect via the $\left(M \boldsymbol{\nabla} \cdot \mathbf{v}_{\mathbf{1}}\right)^{\prime}$ and $\left(M_{q} \boldsymbol{\nabla} \cdot \mathbf{v}_{\mathbf{1}}\right)^{\prime}$ transport terms according to (12). However, in the aerosol absorption forcing case, such a multiplier effect disappears when the solar radiation anomalies at TOA are zero by definition. Under this circumstance, regional tropical precipitation anomalies can be created by evaporation, although with no multiplier effect. Furthermore, the evaporation is constrained by the surface heat flux balance and, thus, is just a fraction of the aerosol solar absorption with opposite sign. Therefore, the aerosol absorption impact on precipitation is less effective than that of aerosol reflection in convective regions when surface heat fluxes are in approximate equilibrium. In the $1 \mathrm{D}$ case, the changes in $E^{\prime}$ due to the surface energy balance are the only way to change precipitation, so attention has focused on these, even though they are small compared to changes due to transport terms. In the solar absorption case in Fig. 5,

TABLE 1 . Summary of moist static energy and moisture budget balances that make tropical regional precipitation anomalies behave differently from a $1 \mathrm{D}$ radiative convective model, especially with respect to absorption. The case for land or equilibrated mixed layer with $F_{s}^{\prime}=0$ is used.

\begin{tabular}{lc}
\hline \hline \multicolumn{1}{c}{ 3D case } & 1D case \\
\hline$P^{\prime}=\left(M_{q} \nabla \cdot \mathbf{v}_{\mathbf{1}}\right)^{\prime}-\langle\mathbf{v} \cdot \nabla q\rangle^{\prime}+E^{\prime}$ & $P^{\prime}=E^{\prime}$ \\
$F_{t}^{\prime}=\left(M \nabla \cdot \mathbf{v}_{\mathbf{1}}\right)^{\prime}+\langle\mathbf{v} \cdot \nabla q\rangle^{\prime}$ & $F_{t}^{\prime}=0$ \\
Tropical regional precipitation & Surface energy partition \\
$\quad$ anomalies mostly due to energy & affects $E^{\prime}$ \\
and moisture transports; little & \\
affected by aborption; & \\
$E^{\prime}$ secondary & \\
\hline
\end{tabular}


(a) $\mathrm{T}(1000 \mathrm{hPa})$ Diff in DJF: ECHAM4

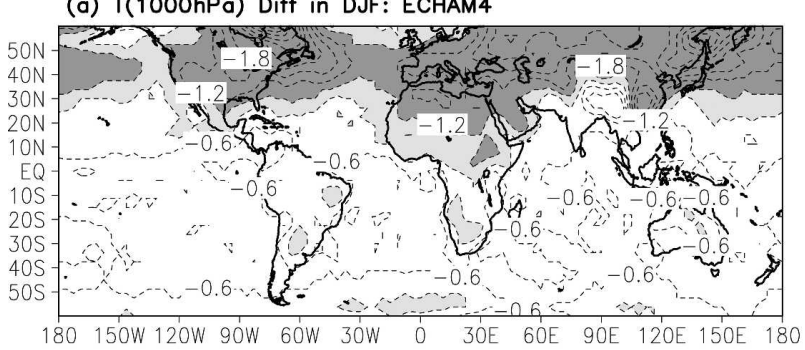

(b) $\mathrm{q}(1000-700 \mathrm{hPa})$ Diff

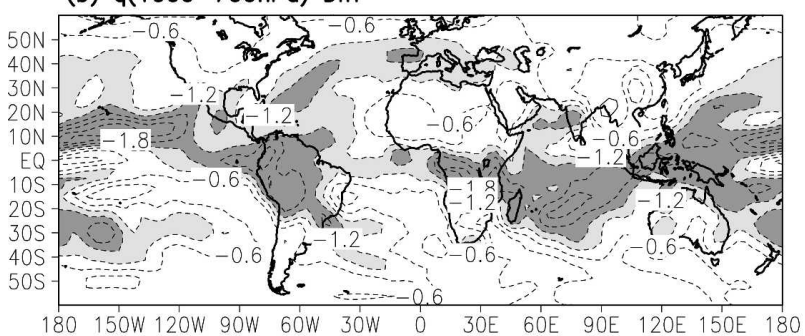

(c) Fs Diff

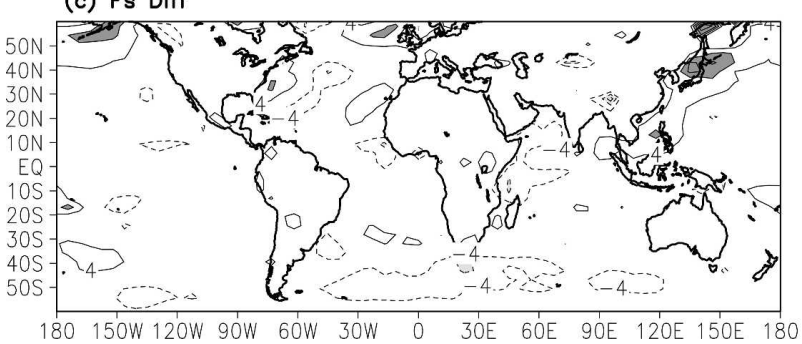

(d) Fnet Diff

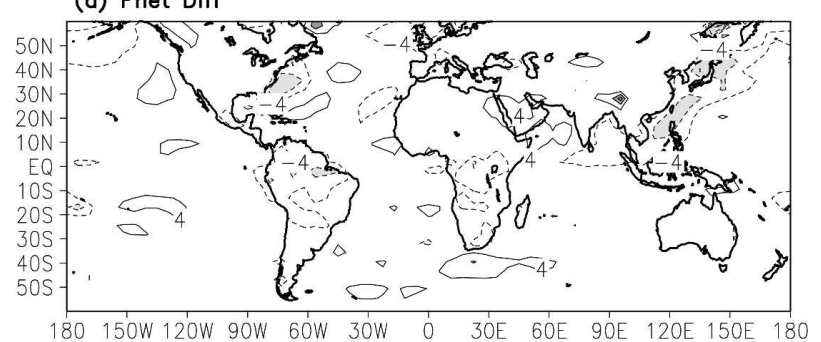

(e) OLR Diff

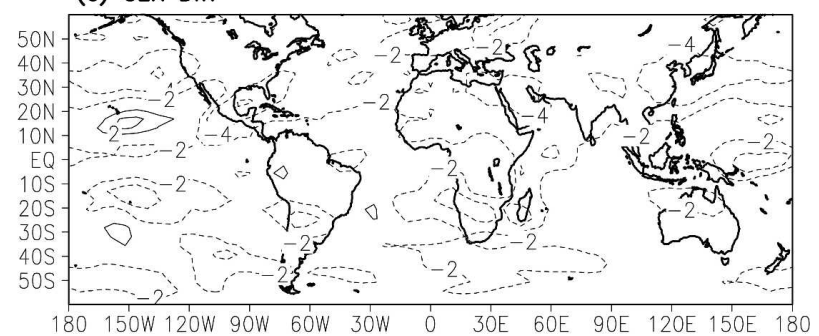

(f) E Diff

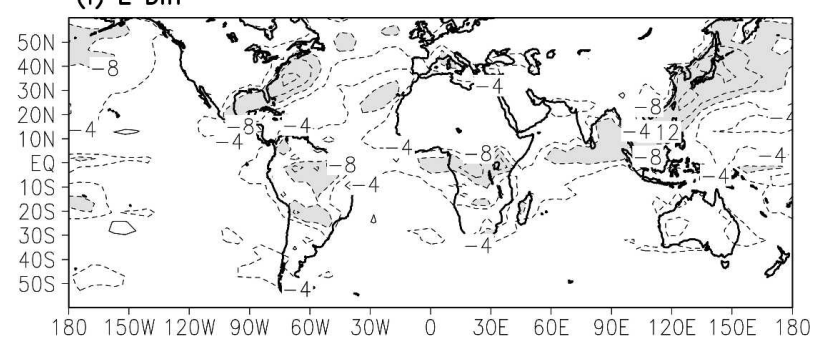

FIG. 6. As in Fig. 1 except for other ECHAM4 variables: (a) near-surface temperature (1000 hPa), (b) low tropospheric moisture $\left(1000-700 \mathrm{hPa}\right.$ ), (c) $F s^{\prime}$, (d) $F^{\text {net }^{\prime}}$, (e) OLR, and (f) evaporation. The moisture is in energy units, i.e., with latent heat per unit mass, $L$, absorbed. Contour interval for (a) and (b) is $0.3^{\circ} \mathrm{C}$ with dark shading above $1.2^{\circ} \mathrm{C}$ and light shading between $0.9^{\circ}$ and $1.2^{\circ} \mathrm{C}$. Contour interval is $4 \mathrm{~W} \mathrm{~m}^{-2}$ for (c), (d), and (f) and $2 \mathrm{~W} \mathrm{~m}^{-2}$ for (e), with dark shading above $8 \mathrm{~W} \mathrm{~m}^{-2}$ and light shading below $-8 \mathrm{~W} \mathrm{~m}^{-2}$.

the evaporation changes are less than $1 \mathrm{~W} \mathrm{~m}^{-2}$, so do not account for the precipitation anomalies.

\section{c. Diagnosis}

Before using QTCM to diagnose the aerosol effects in the ECHAM4 simulations, other components of the QTCM runs, shown in Fig. 3, are compared to the ECHAM4 simulations. In general, the variations of the ECHAM4 runs (Fig. 6) are mimicked by the QTCM simulations (Fig. 7), but the amplitudes of surface temperature, low-level moisture, and evaporation in the QTCM runs are slightly weaker than those in the ECHAM4 runs. Note that the values of the shading in Figs. 7a and $7 \mathrm{~b}$ are different from those in Figs. $6 \mathrm{a}$ and $6 \mathrm{~b}$. The near-surface temperature is decreased globally, more so in the Northern Hemisphere than in the Southern Hemisphere since most aerosols are emitted in the Northern Hemisphere (Figs. 6a and 7a). The surface temperature anomalies are relatively smooth longitudinally. Comparing to the tropospheric temperature anomalies (Figs. $1 \mathrm{~b}$ and $3 \mathrm{~b}$ ), the surface temperature anomalies are colder at higher latitudes where aerosol concentration is high, but warmer (less negative) at lower latitudes.

Unlike the temperature anomalies, the moisture anomalies in the lower troposphere (Fig. 6b for ECHAM4 and Fig. 7b for QTCM) are correlated with regions of mean convection (the thick dashed lines in Figs. 1 and 3), having the larger negative anomalies in convective regions and much smaller negative anomalies over nonconvective regions. These spatial patterns of the moisture and temperature anomalies strongly suggest that similar mechanisms to the global warming case might influence the regional tropical precipitation through interaction with moist dynamical processes, as will be discussed later. Another interesting point is that the strongest response in moisture is often found over regions where aerosol concentration is not high. This further indicates that remote effects through moist dynamical processes are active in the response to aerosol forcing.

Over regions where the precipitation anomalies are 
(a) Ts Diff in DJF: QTCM

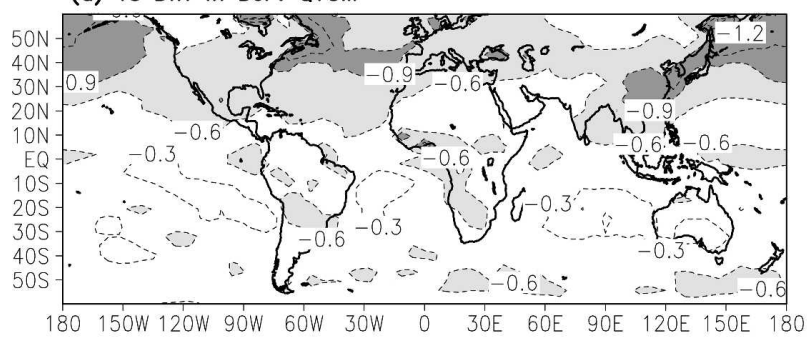

(b) $\mathrm{q}(1000-700 \mathrm{hPa})$ Diff

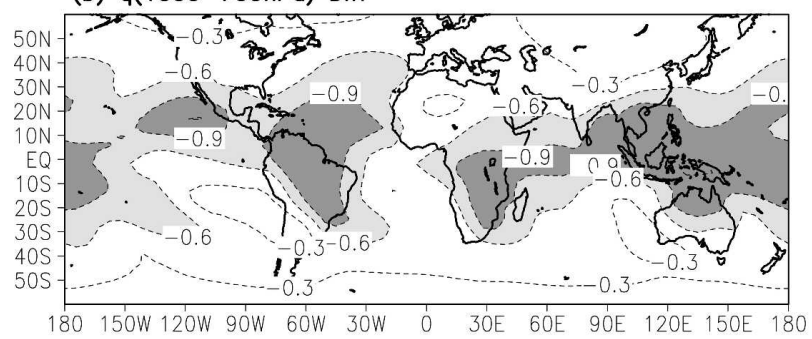

(c) Fs Diff

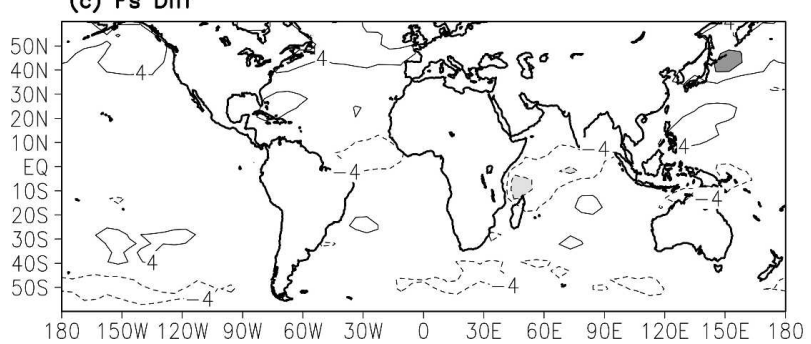

(d) Fnet Diff

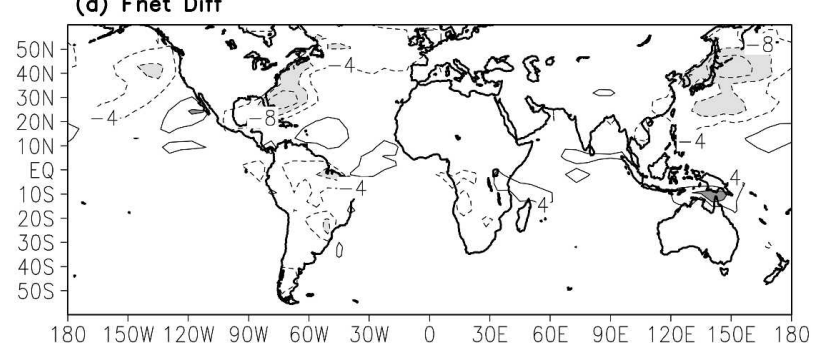

(e) OLR Diff

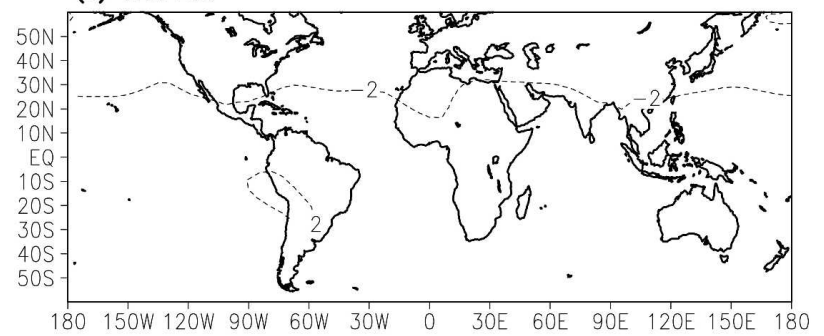

(f) E Diff

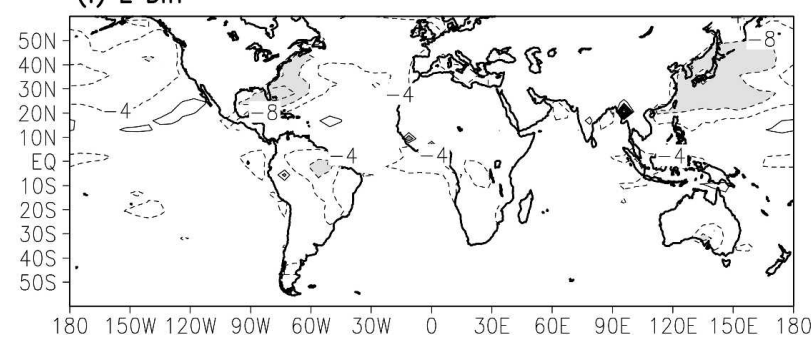

FIG. 7. As in Fig. 6 except for the QTCM simulations and surface temperature in (a). Dark shading is above $0.9^{\circ} \mathrm{C}$ and light shading is between $0.6^{\circ}$ and $0.9^{\circ} \mathrm{C}$.

large, net surface flux $F_{s}^{\prime}$ is smaller than other terms in the moist static energy budget equation (Figs. $6 \mathrm{c}$ and $7 \mathrm{c}$ ) because evaporation, sensible heat, and net longwave radiation balance the net solar radiation anomalies. This balance holds particularly well over land (over oceans, some $F_{s}$ anomalies occur due to seasonal variations). Essentially, the surface temperature anomalies are just a by-product of the surface heat flux balance and should not be viewed as a forcing. This is not like a case with strong ocean heat transports, which would yield large $F^{\text {net' }}$ associated with the surface temperature anomalies. This surface heat flux balance is an important step in the pathway of inducing the regional tropical precipitation anomalies, but its net impact on climate heating in the moist static energy budget is small. Since $F_{s}^{\prime}$ is small, $F^{\text {net' }}$ (Figs. 6d and 7d) is primarily associated with the net heat flux at the TOA, $F_{t}^{\prime}$, in regional imbalances. Here $F_{t}^{\prime}$ is dominated by the aerosol solar reflection, which is partially canceled by outgoing longwave radiation (OLR) anomalies on a regional basis. On broader scales, such as the global scale, the aerosol solar reflection and OLR anomalies will cancel each other (Figs. 6e and 7e). To balance the reduced downward solar radiation, evaporation is generally suppressed (Figs. 6f and 7f) and its horizontal distribution coincides well with the downward solar radiation anomalies at the surface (Fig. 2c; Liepert et al. 2004). Evaporation anomalies have a direct effect associated with moisture budget on the precipitation anomalies but, when $F_{s}^{\prime} \approx 0$, not on the low-level convergence $\boldsymbol{\nabla} \cdot \mathbf{v}_{\mathbf{1}}^{\prime}$.

To further examine impacts of the aerosol forcing on regional precipitation, the moisture and moist static energy budgets in QTCM are analyzed. The precipitation anomalies are determined by four terms on the right of (1). From the moisture budget analysis shown in Figs. 7 and 8, the combination of the first two terms $\left(M_{q} \boldsymbol{\nabla} \cdot \mathbf{v}_{\mathbf{1}}\right)^{\prime}$ : that is, the moisture divergence, dominates the regional tropical precipitation changes and its spatial pattern is very similar to the distribution of the precipitation anomalies (Figs. 3a and 8a). This $\left(M_{q} \boldsymbol{\nabla} \cdot \mathbf{v}_{\mathbf{1}}\right)^{\prime}$ term is central to the dynamic feedback that can be diagnosed using the moist static energy budget to estimate $\boldsymbol{\nabla} \cdot \mathbf{v}_{\mathbf{1}}^{\prime}$. In the Tropics, the direct effects of evaporation anomalies and anomalous horizontal transport of moisture $-(\mathbf{v} \cdot \nabla q)^{\prime}\left(\approx 6 \mathrm{~W} \mathrm{~m}^{-2}\right)$ are not negligible in 
(a) (madiv)a Diff (DJF): QTCM

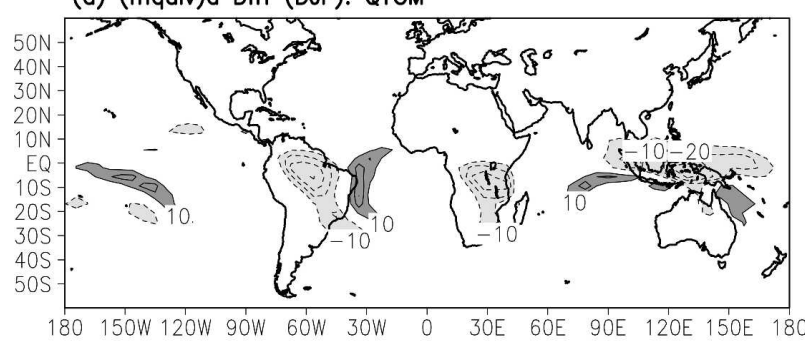

(b) -vdq Diff

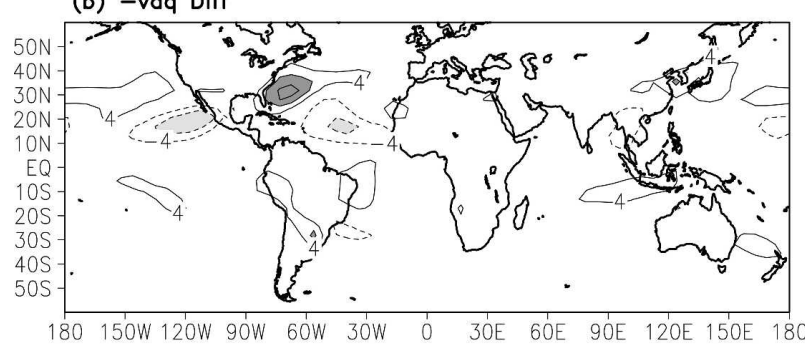

(c) Mdiva Diff

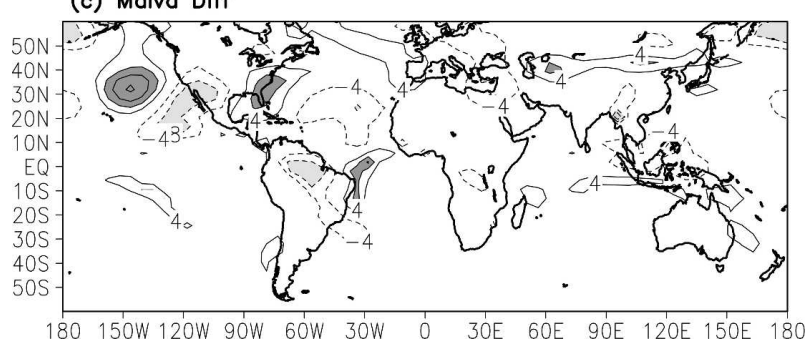

the moisture budget (Figs. $8 \mathrm{~b}$ and Fig. 7f), but they are smaller than those effects via $\boldsymbol{\nabla} \cdot \mathbf{v}_{\mathbf{1}}^{\prime}$ (Fig. 8a) in the moist static energy budget $\left(\approx 35 \mathrm{~W} \mathrm{~m}^{-2}\right)$. Note that $-(\mathbf{v} \cdot \nabla q)^{\prime}$ has a multiplier effect $(\bar{M} q / \bar{M} \approx 4)$ through the moist static energy budget (Yu et al. 1998) according to (12).

The value of $\boldsymbol{\nabla} \cdot \mathbf{v}_{\mathbf{1}}^{\prime}$ can be calculated from $\bar{M} \boldsymbol{\nabla} \cdot \mathbf{v}_{\mathbf{1}}^{\prime}$ in the moist static energy budget, which is similar to the distribution of $\left(M_{q} \boldsymbol{\nabla} \cdot \mathbf{v}_{\mathbf{1}}\right)^{\prime}$ in the Tropics. Thus, those effects associated with $\boldsymbol{\nabla} \cdot \mathbf{v}_{\mathbf{1}}^{\prime}$ [the rhs of (6)] will be enhanced by a factor of $\bar{M} q / \bar{M}$. For instance, $-(\mathbf{v} \cdot \nabla q)^{\prime}$ $\approx 6 \mathrm{~W} \mathrm{~m}^{-2}$ over Northeast Brazil, but it contributes 24 $\mathrm{W} \mathrm{m} \mathrm{m}^{-2}(6 \times 4)$ of the regional precipitation anomalies via $\boldsymbol{\nabla} \cdot \mathbf{v}_{\mathbf{1}}^{\prime}$. The analysis of the QTCM moist static energy budget indicates that $-M^{\prime} \nabla \cdot \overline{\mathbf{v}}_{\mathbf{1}},-[\mathbf{v} \cdot \nabla(T+q)]^{\prime}$ and $F^{n e t^{\prime}}$ are all contributing to $\bar{M} \boldsymbol{\nabla} \cdot \mathbf{v}_{\mathbf{1}}^{\prime}$ (Fig. 8c), but the importance of each term is different in different locations (see Figs. 8d, 8e, and 7d). In the Tropics, particularly over the summer hemisphere, the term $-(\mathbf{v} \cdot \nabla T)^{\prime}$ tends to be small (not shown), so the values of $-[\mathbf{v} \cdot \nabla(T+q)]^{\prime}$ (Fig. 8e) are mainly determined by $-(\mathbf{v} \cdot \nabla q)^{\prime}\left(\right.$ Fig. 8b). Thus, $-(\mathbf{v} \cdot \nabla q)^{\prime}$ is used in the discussion instead of $-[\mathbf{v} \cdot \nabla(T+q)]^{\prime}$. The term $-M^{\prime} \boldsymbol{\nabla} \cdot \overline{\mathbf{v}}_{\mathbf{1}}$ is associated with the $M^{\prime}$ mechanism discussed in CN04, while $-(\mathbf{v} \cdot \nabla q)^{\prime}$ is associated with the (d) -Madivm Diff

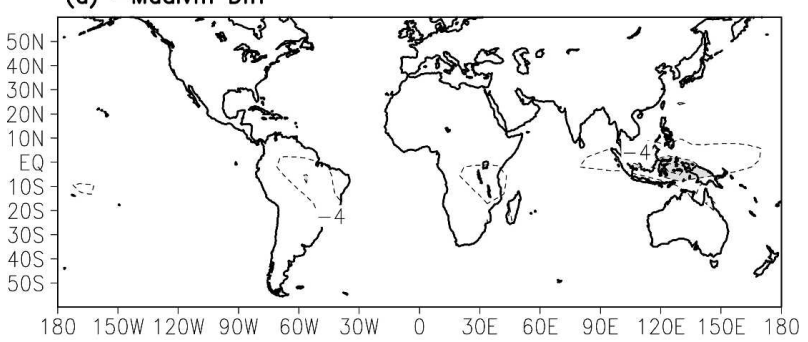

(e) $-(v d(q+T)) a$ Diff

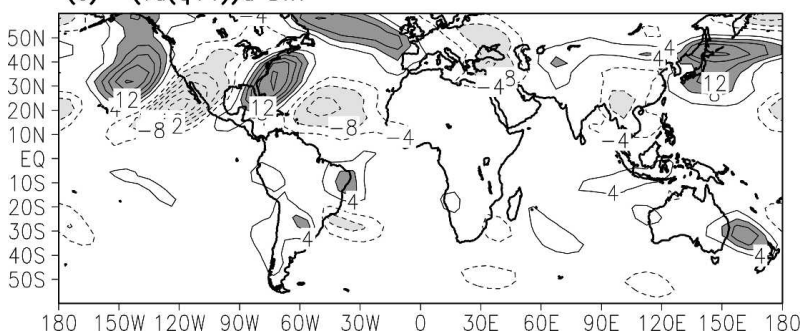

FIG. 8. As in Fig. 7 except for moisture and moist static energy budget terms (a) $\left(M q \nabla \cdot \mathbf{v}_{\mathbf{1}}\right)^{\prime}$, (b) $-\langle\mathbf{v} \cdot \nabla q\rangle^{\prime}$, (c) $\bar{M} \boldsymbol{\nabla} \cdot \mathbf{v}_{\mathbf{1}}{ }^{\prime}$, (d) $-M^{\prime} \nabla \cdot \overline{\mathbf{v}}_{\mathbf{1}}$, and (e) $-\langle\mathbf{v} \cdot \nabla(q+T)\rangle^{\prime}$. Contour interval is $10 \mathrm{~W}$ $\mathrm{m}^{-2}$ with dark shading above $30 \mathrm{~W} \mathrm{~m}^{-2}$ and light shading below $-30 \mathrm{~W} \mathrm{~m}^{-2}$ for (a). Contour interval is $4 \mathrm{~W} \mathrm{~m}^{-2}$ with dark shading above $8 \mathrm{~W} \mathrm{~m}^{-2}$ and light shading below $-8 \mathrm{~W} \mathrm{~m}^{-2}$ for (b)-(e).

upped-ante mechanism. Negative values of $-M^{\prime} \boldsymbol{\nabla} \cdot \overline{\mathbf{v}}_{\mathbf{1}}$ (Fig. 8d) are found over convective regions, so the $M^{\prime}$ mechanism reduces precipitation over convective regions. Positive values of $-(\mathbf{v} \cdot \nabla q)^{\prime}$ are found over margins of convective regions, so the upped-ante mechanism enhances precipitation over those regions. The $M^{\prime}$ and upped-ante mechanisms discussed here are similar to those in the global warming case, but with opposite effects on regional tropical precipitation. This is because the aerosol forcing cools the troposphere through radiative feedbacks and wave dynamics, while greenhouse gases warm the troposphere. The colder tropospheric temperature (Figs. $1 \mathrm{~b}$ and $3 \mathrm{~b}$ ) induces negative low-level moisture anomalies in convective regions (Figs. 6b and 7b) through interaction with convection. The gross moist stability is increased due to the negative low-level moisture anomalies producing $-M^{\prime} \boldsymbol{\nabla} \cdot \overline{\mathbf{v}}_{\mathbf{1}}$ (Fig. 8d), so the precipitation in convective regions is reduced by the $M^{\prime}$ mechanism. Controlled by different mechanisms, such as evaporation, the low-level moisture over nonconvective regions is decreased less than over convective regions (Figs. $6 \mathrm{~b}$ and $7 \mathrm{~b}$ ). The gradient of the anomalous low-level moisture induces $-(\mathbf{v} \cdot \nabla q)^{\prime}$ (Fig. 8b) where transport occurs from nonconvective regions to convective regions and thus positive precipi- 
tation over these margins of convective regions by the upped-ante mechanism.

Here $F^{\text {net' }}$ plays two roles in processes changing regional tropical precipitation. The first role is associated with a local effect that induces local reductions in lowlevel convergence where there is increased solar reflection by aerosols. The second effect is remote, communicated by the anomalous temperature response. In a steady state, the net solar radiation should balance OLR at the TOA on a global scale. Aerosols reflect solar radiation back to space, so OLR must be reduced to balance the increased outgoing solar radiation anomalies on a global average. This remote effect yields colder temperature anomalies globally. The tropospheric temperature anomalies give $-M^{\prime} \boldsymbol{\nabla} \cdot \overline{\mathbf{v}}_{\mathbf{1}}$ and $(\mathbf{v} \cdot \nabla q)^{\prime}$ terms locally via the $M^{\prime}$ and upped-ante mechanisms.

\section{Local versus remote impact experiments}

The analysis above provides evidence that aerosol climate forcing has both local and remote impacts on the regional precipitation in the Tropics. The local impact is associated with local aerosol absorption and reflection, so the impact should be found over regions with high aerosol concentration. The remote impact is associated with global distributions of temperature and moisture anomalies, which induce the $M^{\prime}$ and uppedante mechanisms found in the QTCM. To provide further tests of the hypothesized local and remote aerosol effects respectively, several experiments were conducted. The first pair uses a target area over South America. During the boreal winter (DJF), the South American region has strong aerosol forcing (Fig. 2) and is also dominated by deep convection, so the South American region is a good place to compare local and remote aerosol effects on regional precipitation. Moreover, both climate models simulate the South American convective zones relatively well, so South America is a good target region to examine both aerosol effects. In the first of this pair, solar reflection and absorption are specified only within the South American region. Since the tropospheric temperature anomalies (not shown) in this experiment are small (less than $0.2^{\circ} \mathrm{C}$ ), the remote effects associated with the $M^{\prime}$ and upped-ante mechanisms are weak. Thus, the precipitation anomalies over South America are contributed mainly by the aerosol local effects. The pattern of the precipitation anomalies over South America is similar to $\bar{M} \boldsymbol{\nabla} \cdot \mathbf{v}_{\mathbf{1}}^{\prime}$, which is associated with low-level convergence anomalies, that is, $\boldsymbol{\nabla} \cdot \mathbf{v}_{\mathbf{1}}^{\prime}$. The low-level convergence anomalies over South America are dominated by $F^{\text {net' }}$ (Fig. 9). Comparing Fig. 9a to the control experiment in Fig. 3a, the negative (a) Prec Diff (DJF): QTCM (South America)

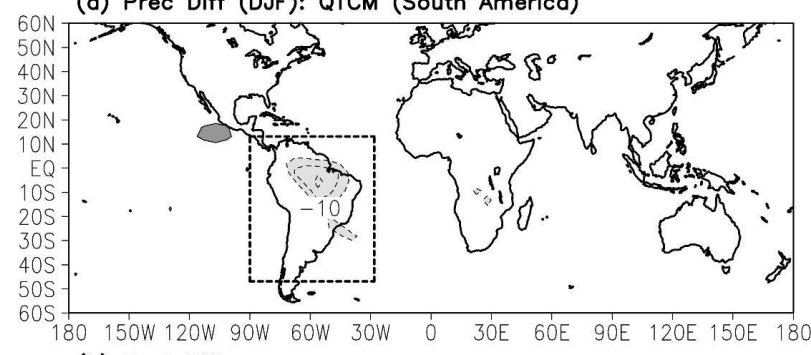

(b) Fnet Diff

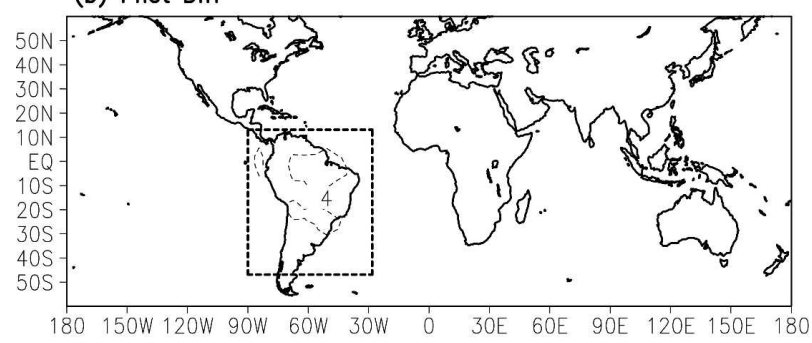

(c) Mdiva Diff

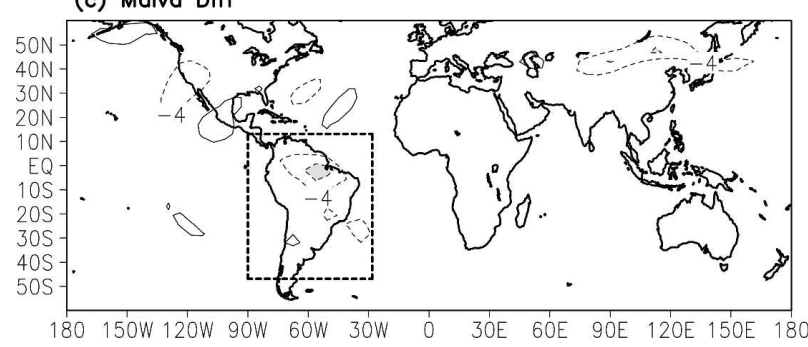

FIG. 9. As in Fig. 3 except for the experiment with the aerosol forcing only within the box around South America. (a) Precipitation with contour interval $10 \mathrm{~W} \mathrm{~m}^{-2}$, (b) $F^{\text {net' }}$ with contour interval $4 \mathrm{~W} \mathrm{~m}^{-2}$, and (c) $\bar{M} \boldsymbol{\nabla} \cdot \mathbf{v}_{\mathbf{1}}^{\prime}$, with contour interval $4 \mathrm{~W} \mathrm{~m}^{-2}$.

precipitation anomalies over the South American convective region are weaker than those in Fig. 3a, and the positive precipitation anomalies near Northeast Brazil disappear. The local forcing creates negative precipitation anomalies but does not induce positive precipitation anomalies. Over land, $F_{s}^{\prime}$ is close to zero, so $F^{\text {net' }}$ is determined by $F_{t}^{\prime}$, which is determined by the negative solar radiation anomalies at TOA (Fig. 2b). The negative $F^{\text {net' }}$ disfavors convection, so the associated precipitation is decreased.

In the second pair of the South American experiment, the aerosol forcing associated with the solar reflection and absorption is specified only outside the box over South America (Fig. 10). This is used to examine the aerosol remote effect on South America. Over the target region, positive (negative) precipitation anomalies are found over the east (west) (Fig. 10a). The horizontal distribution of temperature and moisture anomalies is similar to that in Figs. 3 and 7, but the amplitudes are slightly weaker. Thus, the $M^{\prime}$ and upped-ante mechanisms induced by the tropospheric temperature and moisture anomaly patterns are re- 
(a) Prec Diff (DJF): QTCM (outside of South America)

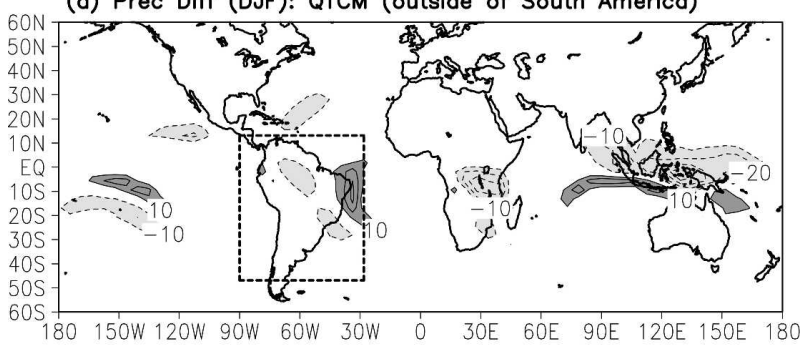

(b) $\mathrm{T}(850-200 \mathrm{hPa})$ Diff

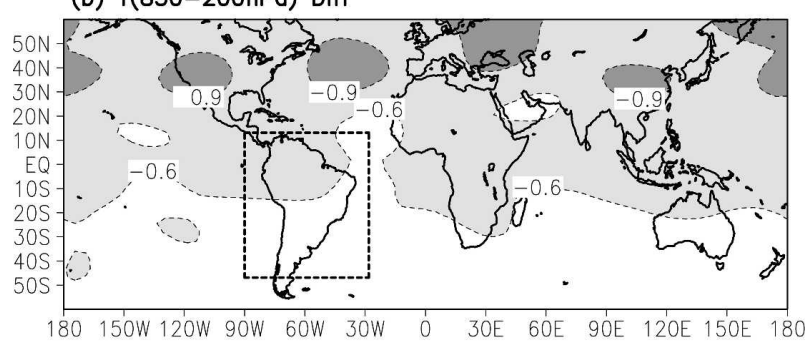

(c) $\mathrm{q}(1000-700 \mathrm{hPa})$ Diff

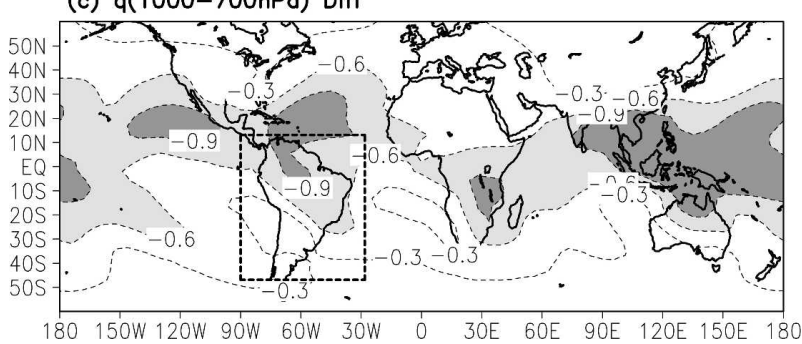

FIG. 10. As in Fig. 9 except for the experiment with the aerosol forcing only outside the box around South America: (a) precipitation, (b) tropospheric temperature (850-200 hPa), and (c) lowlevel moisture (1000-700 hPa).

sponsible for the anomalous precipitation over the South American region in this experiment. Positive precipitation anomalies over Northeast Brazil are found in Fig. 10a but not in Fig. 9a. This indicates that the upped-ante mechanism is the dominant mechanism inducing the positive precipitation anomalies. The magnitude of the negative precipitation anomalies is less than half of those in Fig. 9a, so the local effect is larger than the remote effect in producing the negative precipitation anomalies over the South American convective region. The sum of the South American precipitation anomalies in Figs. 9 and 10 is roughly equal to that of the precipitation anomalies in Fig. 3. Overall, the positive precipitation anomalies near Northeast Brazil are contributed mostly by the remote effect associated with the upped-ante mechanism, while the negative precipitation anomalies in the west are contributed by both the aerosol local effect and the aerosol remote effect associated with the $M^{\prime}$ mechanism.

Another experiment examining the aerosol remote effect is performed with the prescribed aerosol forcing only within a zonal band between $20^{\circ}$ and $50^{\circ} \mathrm{N}$, where most aerosol emissions are taking place. Widespread cold temperature anomalies occur over the Tropics (Fig. 11b), almost half the magnitude of those in the full forcing case (Fig. 3b). Tropospheric temperature anomalies due to the aerosol cooling effects at midlatitudes are transmitted to the Tropics presumably by transient heat fluxes limiting temperature gradients. The temperature anomalies then propagate throughout the Tropics by wave dynamics. The colder tropospheric temperature anomalies in the Tropics cause horizontal gradients of low-level moisture anomalies through the QE-mediated effect. The $M^{\prime}$ and upped-ante mechanisms then affect regional tropical precipitation. The largest precipitation anomalies in this experiment (Fig. 11a) occur over the Tropics despite the aerosol forcing being set to zero. Comparing to the full experiment shown in Fig. 4, the midlatitude aerosol effect contributes half of the precipitation anomalies over most tropical regions. Some caveats on this experiment are that gradients at the edge of the applied aerosol region appears to affect transient moisture transport by winter storms, contributing negative precipitation anomalies in the Northern Hemisphere subtropics, such as in the tropical North Atlantic and western Pacific.

To further examine the remote effects associated with tropospheric temperature, an experiment is conducted in which the tropospheric temperature anomalies obtained from the full aerosol experiment shown in Fig. $3 b$ are specified in the convective scheme. The pattern of the precipitation anomalies in Fig. 12a is similar to those in the full aerosol experiment (Fig. 3b),

(a) Prec Diff (DJF): QTCM (2ON-5ON)

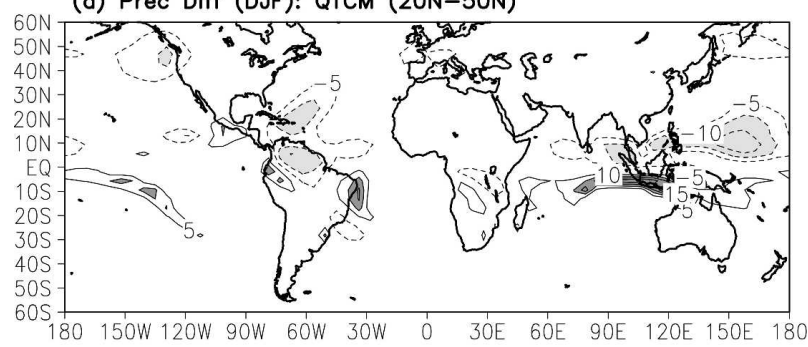

(b) $\mathrm{T}(850-200 \mathrm{hPa})$ Diff

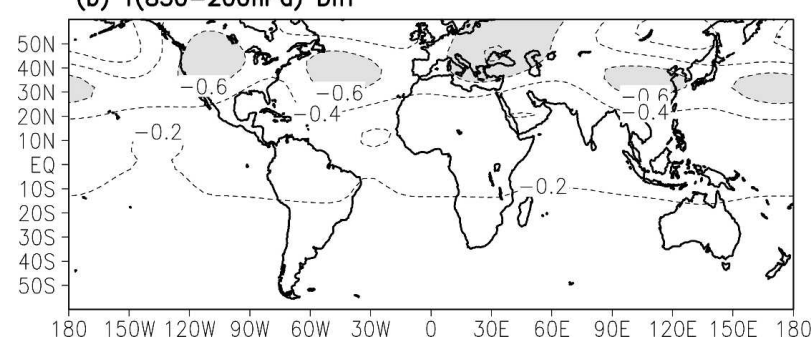

FIG. 11. As in Fig. 3 except for the experiment with the aerosol forcing only within $20^{\circ}-50^{\circ} \mathrm{N}$ : (a) precipitation and (b) tropospheric temperature $(850-200 \mathrm{hPa})$. 
(a) Prec Diff (DJF): QTCM (Qc-Ta)

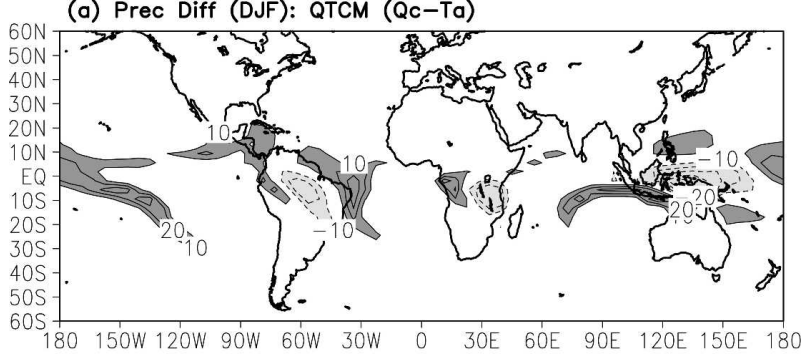

(b) $\mathrm{q}(1000-700 \mathrm{hPa})$ Diff

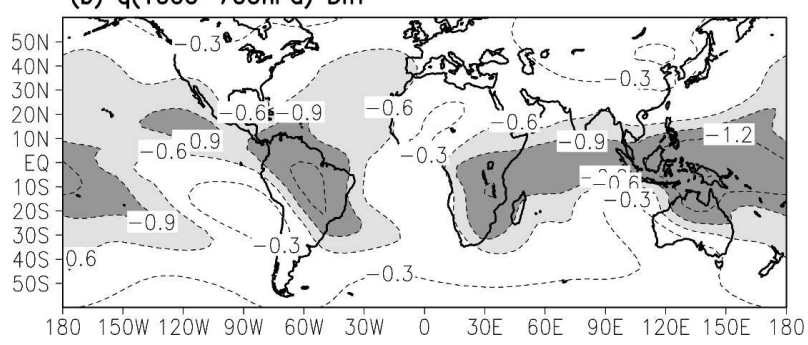

FIG. 12. (a) Precipitation and (b) low-level moisture differences between the QTCM PD and PI period for the experiment with modified tropospheric temperature anomalies specified in the convection scheme.

and the magnitude of the anomalies is also comparable over most regions except for those with high aerosol concentration, such as South America and Africa. The associated low-level moisture anomalies are also similar to those in Fig. 7b. This demonstrates that the QE-mediated impacts that depend fundamentally on deep convection initiate low-level moisture changes and the change of the low-level moisture is not simply a Clausius-Clapeyron response to surface warming. We also note that surface temperature anomalies (not shown) in this experiment are less than half those in the control, consistent with our claim that surface temperature is essentially a by-product.

\section{Discussion}

The intermediate atmospheric model QTCM qualitatively reproduces aspects of the ECHAM4 simulations of present-day minus preindustrial climate anomalies due to aerosol direct and indirect effects when forced by the aerosol-induced solar radiative flux anomalies from ECHAM4. The widespread cooling due to aerosol reflection of solar radiation is comparable in surface temperature anomalies and tropospheric temperature. Since there is no sea ice in QTCM, amplitudes of the temperature anomalies at high latitudes are weaker in the QTCM simulations than in the ECHAM4 simulations. The spatial pattern of tropospheric temperature anomalies-which is key to some of the effects below-is well reproduced, with dynami- cal effects smoothing and spreading the cooling relative to the aerosol forcing. The associated precipitation anomalies present a much more complicated spatial distribution. Negative precipitation anomalies are found over convective regions, while positive precipitation anomalies occur over margins of convective regions. Thus, the aerosol effects on precipitation are complex on a regional scale.

We note some caveats on this approach. Cloudiness in the QTCM simulations is fixed so as not to double count cloud-radiative feedbacks, which are included in the solar forcing from ECHAM4. In QTCM, the vertical profile of the temperature variations is prescribed, so the change of the vertical temperature structure induced by the aerosol absorption effects cannot be simulated. However, the large-scale temperature anomalies in ECHAM4 tend to have a deep structure and this is captured.

A pair of experiments was conducted to approximately separate impacts of aerosol absorption and reflection, respectively, on the climate system. Both aerosol absorption and reflection effects cool the surface with similar amplitudes, but the reflection effect is much larger than the absorption effect in cooling the climate system and producing anomalous precipitation. This occurs because at the time scales considered here, both land and ocean are equilibrated to have a small net surface heat flux anomaly. Absorption thus mainly affects the partitioning of surface heat flux to the atmosphere but does not affect the net flux heating of the atmospheric column since other surface fluxes compensate. It also does not change the TOA anomaly (in the definition used here), so it does not change the overall heat absorbed in the climate system.

We distinguish between local and remote effects of aerosol forcing. Aerosol effects that involve the dynamically direct impact of the change in radiative fluxes on the column impacting the energy budget (and hence vertical motion in the Tropics) tend to be highly local. On the other hand, tropospheric temperature anomalies tend to spread to broad spatial scales and this, in turn, has remote impacts on tropical precipitation in a manner akin to ENSO teleconnections (NCS03) or global warming (CNO4). We note that the terms local and remote are most appropriate when the aerosol forcing is localized. If the aerosol were evenly distributed, the effects would overlap spatially.

The local effect can be understood from the aerosol TOA forcing (Fig. 2b). Aerosols absorb and reflect solar radiation, so the solar radiation reaching the surface is reduced. This anomalous solar radiation is balanced by evaporation, sensible heat, and longwave radiation emitted by the surface associated with colder surface 
temperature, so the associated surface heat flux anomalies are close to zero. Thus, the net radiative fluxes at the TOA, $F_{t}^{\prime}$, determine $F^{\text {net' }}$, which results in regional imbalances in the energy budget and induces the precipitation anomalies through interaction with convection. In convective zones, the partition between anomalous evaporation, sensible heat, and surface longwave radiation is secondary since convection links moisture and energy budgets.

The remote effects are associated with two mechanisms: the anomalous gross moist stability $\left(M^{\prime}\right)$ mechanism and the upped-ante mechanism. The widespread cold tropospheric temperature anomalies create a horizontal moisture gradient between convective regions and nonconvective regions. In convective zones, the colder temperature yields reduced low-level moisture in order to maintain convective quasi equilibrium, a process referred to as QE mediation (CN04; Neelin and $\mathrm{Su}$ 2005). Negative low-level moisture anomalies tend to increase the gross moist stability and stabilize the atmosphere. Therefore, convection is suppressed and negative precipitation anomalies are induced over convective regions. This effect is referred to as the $M^{\prime}$ mechanism. Over nonconvective regions where moisture is controlled by different mechanisms, such as the balance between divergence and evaporation, the lowlevel moisture does not decrease as much as in convective regions. The mean circulation thus transports less negative low-level moisture from nonconvective regions into convective regions where negative low-level moisture anomalies are larger. The horizontal advection of moisture enhances the low-level moisture at the margins of convective regions, strengthening convection. Thus, precipitation is increased by this upped-ante mechanism over margins of convective regions where there is strong inflow. As noted in CN04, uncertainties in $M^{\prime}$ are a potential source of climate model disagreement, so effects associated with the $M^{\prime}$ mechanism should be regarded as model dependent.

Over regions with strong aerosol forcing coinciding with convection, the local effect of aerosol contributes a large portion of the negative precipitation anomalies, while the $M^{\prime}$ mechanism contributes only a small portion of the negative precipitation anomalies. This is seen, for instance, in local versus remote experiments over a South American target region. The upped-ante mechanism is responsible for the positive precipitation anomalies over margins of convective regions, such as Northeast Brazil. The importance of the aerosol local and remote effects differs from region to region. For instance, over the Maritime Continent where the aerosol concentration is low, most precipitation changes are contributed by remote effects. An experiment that specifies tropospheric temperature anomalies from the control run within the convection scheme-and thus includes only the remote effects-produces many regions of precipitation anomalies resembling those of the control. A surprising portion of the tropical temperature and precipitation response is reproduced by specifying midlatitude aerosol forcing alone, indicating the importance of midlatitude to Tropics remote effects.

Acknowledgments. This work was supported under National Science Council Grant 92-2111-M-001-001, the National Science Foundation Grant ATM-0082529, and National Oceanic and Atmospheric Administration Grant NA05OAR4310007. Comments from Dr. Chris Bretherton and two anonymous reviewers were helpful for improving the quality of this paper.

\section{REFERENCES}

Allen, M. R., and W. J. Ingram, 2002: Constraints on future changes in climate and the hydrologic cycle. Nature, 419, 224232 .

Betts, A. K., and M. J. Miller, 1993: The Betts-Miller scheme. The Representation of Cumulus Convection in Numerical Models of the Atmosphere, Meteor. Monogr., No. 46, Amer. Meteor. Soc., 107-121.

Cess, R. D., G. L. Potter, S. J. Ghan, and W. L. Gates, 1985: The climatic effects of large injections of atmospheric smoke and dust: A study of climate feedback mechanisms with one- and three-dimensional climate models. J. Geophys. Res., 90, 12 937-12 950.

Chou, C., and J. D. Neelin, 1996: Linearization of a longwave radiation scheme for intermediate tropical atmospheric models. J. Geophys. Res., 101, 15 129-15 145.

— Geophys. Res. Lett., 26, 1295-1298.

— , and _ 2004: Mechanisms of global warming impacts on regional tropical precipitation. J. Climate, 17, 2688-2701.

—_— in an idealized monsoon. Quart. J. Roy. Meteor. Soc., 127, 1869-1891.

Feichter, J., E. Roeckner, U. Lohmann, and B. Liepert, 2004: Nonlinear aspects of the climate response to greenhouse gas and aerosol forcing. J. Climate, 17, 2384-2398.

Fu, Q., and K. N. Liou, 1993: Parameterization of the radiative properties of cirrus clouds. J. Atmos. Sci., 50, 2008-2025.

Hansen, J., M. Sato, and R. Ruedy, 1997: Radiative forcing and climate response. J. Geophys. Res., 102, 6831-6864.

Harshvardhan, R. Davies, D. A. Randall, and T. G. Corsetti, 1987: A fast radiation parameterization for general circulation models. J. Geophys. Res., 92, 1009-1016.

Houghton, J. T., Y. Ding, D. J. Griggs, M. Noguer, P. J. van der Linden, X. Dai, K. Maskell, and C. A. Johnson, Eds., 1995: Climate Change 2001: The Scientific Basis. Cambridge University Press, $881 \mathrm{pp}$.

Jacobson, M. Z., 2001: Strong radiative heating due to the mixing state of black carbon in atmospheric aerosols. Nature, 409, 695-697. 
Kaufman, Y. J., D. Tanré, and O. Boucher, 2002: A satellite view of aerosols in the climate system. Nature, 419, 215-223.

Liepert, B. G., J. Feichter, U. Lohmann, and E. Roeckner, 2004: Can aerosols spin down the water cycle in a warmer and moister world? Geophys. Res. Lett., 31, L06207, doi:10.1029/ 2003GL019060.

Lohmann, U., and G. Lesins, 2002: Stronger constraints on the anthropogenic indirect aerosol effect. Science, 298, 10121016.

— J J. Feichter, C. C. Chuang, and J. E. Penner, 1999: Predicting the number of cloud droplets in the ECHAM4 GCM. J. Geophys. Res., 104, 9169-9198.

,-- J. E. Penner, and W. R. Leaitch, 2000: Indirect effect of sulfate and carbonaceous aerosols: A mechanistic treatment. J. Geophys. Res., 105, 12 193-12 206.

Menon, S., J. Hansen, L. Nazarenko, and Y. Luo, 2002: Climate effects of black carbon aerosols in China and India. Science, 297, 2250-2253.

Neelin, J. D., and J.-Y. Yu, 1994: Modes of tropical variability under convective adjustment and the Madden-Julian oscillation. Part I: Analytical theory. J. Atmos. Sci., 51, 1876-1894.

— model-Formulation. J. Atmos. Sci., 57, 1741-1766.

- , and H. Su, 2005: Moist teleconnection mechanisms for the tropical South American and Atlantic sector. J. Climate, 18, 3928-3950.

- C. Chou, and H. Su, 2003: Tropical drought regions in global warming and El Niño teleconnections. Geophys. Res. Lett., 30, 2275, doi:10.1029/2003GL018625.

Penner, J. E., X. Dong, and Y. Chen, 2004: Observational evi- dence of a change in radiative forcing due to the indirect aerosol effect. Nature, 427, 231-234.

Ramanathan, V., P. J. Crutzen, J. T. Kiehl, and D. Rosenfeld, 2001: Aerosols, climate, and the hydrological cycle. Science, 294, 2119-2124.

Roeckner, E., T. Siebert, and J. Feichter, 1995: Climatic response to anthropogenic sulfate forcing simulated with a general circulation model. Aerosol Forcing of Climate, R. J. Charlson and J. Heintzenberg, Eds., John Wiley and Sons, 349-362.

Rotstayn, L. D., and U. Lohmann, 2002: Tropical rainfall trends and the indirect aerosol effect. J. Climate, 15, 2103-2116.

Stevens, B., J. Duan, J. C. McWilliams, M. Münnich, and J. D. Neelin, 2002: Entrainment, Rayleigh friction, and boundary layer winds over the tropical Pacific. J. Climate, 15, 30-44.

Su, H., and J. D. Neelin, 2002: Teleconnection mechanisms for tropical Pacific descent anomalies during El Niño. J. Atmos. Sci., 59, 2694-2712.

,-- , and C. Chou, 2001: Tropical teleconnection and local response to SST anomalies during the 1997-1998 El Niño. $J$. Geophys. Res., 106 (D17), 20 025-20 043.

Yu, J.-Y., and J. D. Neelin, 1994: Modes of tropical variability under convective adjustment and the Madden-Julian oscillation. Part II: Numerical results. J. Atmos. Sci., 51, 1895-1914.

- C. Chou, and J. D. Neelin, 1998: Estimating the gross moist stability of the tropical atmosphere. J. Atmos. Sci., 55, 13541372.

Zeng, N., J. D. Neelin, and C. Chou, 2000: A quasi-equilibrium tropical circulation model-Implementation and simulation. J. Atmos. Sci., 57, 1767-1796. 